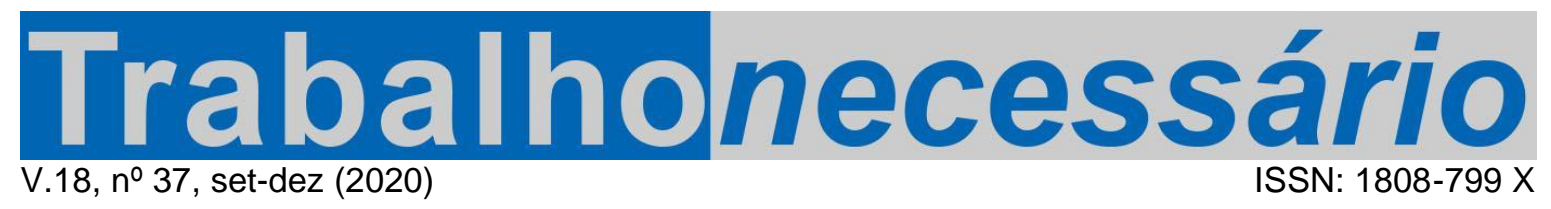

\title{
TECNOLOGIAS DE PRODUÇÃO DA VIDA EM IMAGENS: SABERES DO TRABALHO DA PESCA EM COMUNIDADES RIBEIRINHAS ${ }^{1}$
}

Osvaldo Luís Martins de Castro² Doriedson do Socorro Rodrigues ${ }^{3}$

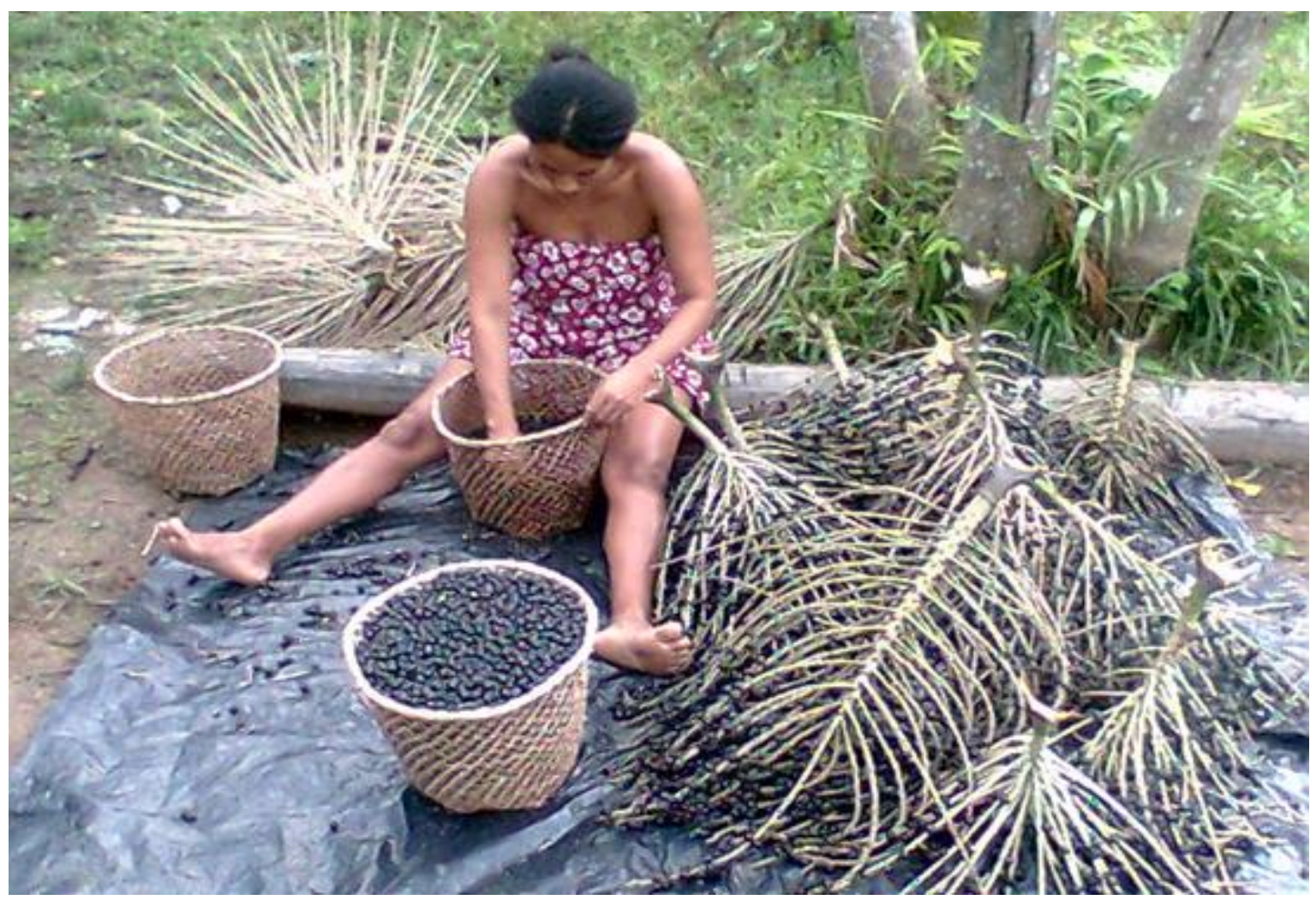

\footnotetext{
${ }^{1}$ Artigo recebido em 14/08/2020. Primeira Avaliação em 14/08/2020. Segunda Avaliação em 27/08/2020. Aprovado em 27/08/2020. Publicado em 25/09/2020.

DOI: http://doi.org/10.22409/tn.v18i37.44.556.

2 Mestre em Currículo e Gestão da Escola Básica, pela Universidade Federal do Pará (UFPA) - Brasil. Docente da Educação Básica, atuando no Ensino Médio e no Ensino Fundamental. Membro do Grupo de Estudos e Pesquisas sobre Trabalho e Educação (GEPTE/UFPA).E-mail: lampamartins@gmail.com; ORCID:0000-0003-4678-6099. Lattes: http://lattes.cnpq.br/6644437163550569.

3 Doutor em Educação pela Universidade Federal do Pará (UFPA) - Brasil. Docente da Universidade Federal do Pará, Campus Universitário do Tocantins/Cametá - Pará, Brasil. Membro do Grupo de Estudos e Pesquisas sobre Trabalho e Educação (GEPTE/UFPA) e do Grupo de Pesquisa História, Educação e Linguagem na Região Amazônica (GPHELRA/UFPA). E-mail: doriedson@ufpa.br ORCID: 0000-0002-5120-2484. Lattes: http://lattes.cnpq.br/1127076028303549.
} 


\title{
Resumo
}

Neste ensaio, apresenta-se um conjunto de fotografias que permitem refletir, a partir do trabalho, o ser social pescador/pescadora artesanal como produtor de saberes manifestos em instrumentos (tecnologias) que caracterizam ações de pesca e extração de recursos outros da floresta, assim como em relações sociais mediadas pelo trabalho dos homens entre si e com a natureza.

Palavras-chave: Fotografias. Saberes do Trabalho da Pesca. Produção da vida.

TECNOLOGÍAS DE PRODUCCIÓN DE LA VIDA EN IMÁGENES: SABERES DEL TRABAJO PESQUERO EN COMUNIDADES RIBEREÑAS

\section{Resumen}

En este ensayo se presenta un conjunto de fotografías que permiten reflejar, desde de la acción laboral, el ser social pescador/pescadora artesanal como un productor de saberes que se manifiestan en instrumentos (tecnologías) que caracterizan las acciones de pesca y extracción de diversos recursos de la floresta, así como también en las relaciones sociales mediadas por el trabajo de los hombres, entre sí y con la naturaleza.

Palabras-clave: Fotografías. Saberes del trabajo pesquero. Producción de la vida.

\section{TECHNOLOGIES OF PRODUCTION OF LIFE IN IMAGES: KNOWLEDGE OF THE WORK OF} FISHING IN RIVERINE COMMUNITIES

\begin{abstract}
In this essay, a set of photographs is presented that allow us to reflecting, from work, the social being of the artisanal fishermen/fisherwoman as a producer of manifest knowledge in instruments (technologies) that characterize actions of fishing and extraction of other resources of the forest, as well as in social relations mediated by the work of men among themselves and with nature.
\end{abstract}

Keywords: Photographs. Knowledge of the Work of fishing. Life production.

\section{Introdução}

O Baixo Tocantins é uma das regiões de colonização mais antigas do estado do Pará, Amazônia, sendo constituído por sete municípios - Abaetetuba, Igarapé Miri, Limoeiro do Ajuru, Cametá, Mocajuba, Baião e Oeiras do Pará. E é a partir dessa região, com foco específico no município de Cametá, que apresentamos o presente ensaio a partir um conjunto de fotografias ${ }^{4}$ sobre o mundo de trabalho de pescadores e pescadoras artesanais, produzindo-se uma reflexão sobre saberes do trabalho da pesca, manifestos em instrumentos (tecnologias) e em relações sociais mediadas pelo trabalho dos homens entre si e com a natureza.

Isto posto, salientamos, segundo Almeida (2010, p. 292), que o Baixo Tocantins é região envolvida por um mundo de águas, "[...] organizado pelos rios Moju, Pará e o

\footnotetext{
${ }^{4}$ Todas as fotografias aqui presentes estão com cessão de uso para o presente ensaio.
} 
caudaloso Tocantins", destacando-se que "[...] apenas o município de Oeiras do Pará não é banhado pelo Tocantins, e sim pelo Rio Pará". Todavia, também de acordo com Almeida (2010, p. 292), a região, em maior ou menor profundidade, sofre "[...] os impactos da barragem de Tucuruí, com ênfase para a redução do pescado", afetando a produção da vida das comunidades ribeirinhas, que têm, nesse estuário, as marés condicionando-Ihes a existência em suas diferentes mediações - sociais, políticas, organizativas, produtivas, culturais, por exemplo -, permitindo-lhes também, por meio de típicas embarcações da região, como "cascos (canoas), voadeiras e popopôs nome de embarcação adquirido por conta do ruído do motor [...]", as "[...] relações comerciais entre os agricultores, pescadores e extrativistas com o meio urbano".

E nesse contexto socioambiental, Cametá é território ${ }^{5}$ onde vivem comunidades quilombolas, extrativistas, povos das águas e da floresta, populações urbanas, rurais, campesinas e ribeirinhas, tratando-se de município com mais de 380 anos, com uma população estimada em 137.890 habitantes $^{6}$, tendo a maior parte de seus habitantes vivendo na zona rural e em comunidades ribeirinhas, a partir das quais resultam as fotografias com as quais estabelecemos um diálogo neste ensaio, versando sobre o trabalho de homens e mulheres ribeirinhos ligados ao mundo da pesca artesanal.

Por ribeirinhos, categoria que permite compreender a materialidade produtiva e relacional de homens e mulheres, em suas relações com a natureza e com eles mesmos, entendemos, conforme Neves (2009, p. 70), um conjunto de homens e mulheres que constroem a vida por meio da pesca e extração de recursos da floresta, mas também a partir da agricultura de várzea, vivendo/trabalhando em ambientes na beira de rios, furos, igarapés, com "[...] um modo de vida advogado como sui generis", organizados em comunidades entendidas como "[...] unidade territorial politicamente constituída pelo ideário da solidariedade e da redistribuição fraterna ou vicinal".

Com base também em Neves (2009, p. 68), entendemos que os ribeirinhos, pela "[...] relação com os recursos naturais, são portadores de saberes, técnicas, estratégias e alternativas peculiares à convivência [...]" nesse contexto material de

\footnotetext{
${ }^{5}$ Com base em Souza (2020, p. 13), entendemos também que "[...] os povos/comunidades tradicionais têm o território como "um ambiente simbólico, místico, político, econômico" (SOUZA; BRANDÃO, 2012, p. 3), entendido como o lugar para além de suas fronteiras geopolíticas. Para eles, o significado do território norteia a vida das pessoas que ali vivem e constroem valores em suas experiências de trabalho".

6 Segundo o Instituto Brasileiro de Geografia e Estatística (IBGE, 2019). Acesso a partir de < https://cidades.ibge.gov.br/>.
} 
existência, permeados pelas relações com a natureza, sendo também atingidos, contudo, por ações decorrentes do modo de produção capitalista, como a presença de grandes projetos do interesse do capital, a exemplo da Hidrelétrica de Tucuruí ${ }^{\text {. }}$

Em Cametá, pois, um conjunto de pescadores e pescadoras artesanais, ribeirinhos e ribeirinhas, vivendo no interior de ilhas, vilas, comunidades, distritos, produzindo a vida por meio do trabalho, vai pondo em movimento "[...] forças naturais de seu corpo - braços e pernas, cabeça e mãos, a fim de apropriar-se dos recursos da natureza, imprimindo-Ihes forma útil à vida humana" (MARX, 2008, p. 211), tanto no que se refere à produção de tecnologias, aqui entendidas como instrumentos para a captura de pescado e extração de recursos das florestas, como no que diz respeito ao estabelecimento de relações sociais necessárias à manutenção da vida, constituindo, assim, a própria existência.

Tudo isso acontece no/pelo trabalho, que vai possibilitando a esses sujeitos de história, a partir de suas próprias ações, impulsionar, regular e controlar "[...] seu intercâmbio material com a natureza [...]", de maneira que, "atuando assim sobre a natureza externa e modificando-a, ao mesmo tempo modifica sua própria natureza". Desse modo, "[...] desenvolve as potencialidades nela adormecidas e submete ao seu domínio o jogo das forças naturais" (MARX, 2008, p. 211).

Isso exposto, destacamos que as fotografias aqui reunidas buscam expor cenas do cotidiano da materialidade produtiva de homens e mulheres ribeirinhos/ribeirinhas que constroem tecnologias e relações sócio-comunitárias, a fim de atender suas necessidades de existência, moldando a natureza, em seu sentido amplo, em instrumentos de captura de peixes diversos e para extração de outros recursos da floresta, e também em relações de partilha, colaboração ${ }^{8}$. No dizer de Heller (2008, p. 31-32), diríamos que esse cotidiano é a vida onde esses sujeitos colocam “[...] 'em funcionamento' todos os seus sentidos, todas as suas capacidades intelectuais, suas habilidades manipulativas, seus sentimentos, paixões, ideias,

\footnotetext{
${ }^{7}$ Segundo Rodrigues (2012, p. 219), a "[...] construção da Hidrelétrica de Tucuruí, iniciada durante o período de ditadura militar, foi desencadeada para atender às demandas de grandes projetos industriais que se instalavam na região Norte, como o Complexo Industrial do Alumínio, em Vila do Conde, e a ALBRÁS e ALUNORTE, em Barcarena-PA".

${ }^{8}$ As tecnologias, entendidas como instrumentos de pesca e relações socioculturais, aqui expostas por meio das fotografias, constituem materialidades de um conjunto de ribeirinhos e ribeirinhas da Amazônia, havendo possivelmente outras descrições sobre as mesmas, como as de Furtado (1993) e Moraes (2007). Contudo, para o presente trabalho, toma-se a materialidade de vida de homens e mulheres ribeirinhos e ribeirinhas do município de Cametá-Pará.
} 
ideologias", constituindo-se a "[...] organização do trabalho e da vida privada [...]" “[...] partes orgânicas da vida cotidiana".

Trata-se, assim, de imagens que expõem o cotidiano de saberes do trabalho de pescadores e pescadoras artesanais do Baixo Tocantins, município de Cametá, resultantes, conforme Thompson (1981), de "experiências herdadas" a partir de relações comunitárias estabelecidas entre pais/mães, filhos e filhos, vizinhos e vizinhas, amigos e amigas, trabalhadores e trabalhadoras, em que, de acordo com Thompson (2005, p. 7), "[...] relações sociais e trabalho estão interligados - a jornada de trabalho se alonga e se prolonga conforme as tarefas - e não existe uma grande sensação de conflito entre o trabalho e o passar do dia".

Todavia, há de se registrar que essas populações vêm sendo, também, atacadas em seus modos de existir, como outrora já aludimos, pela lógica de produção capitalista, por meio de grandes projetos minero-energéticos presentes na região, a exemplo da Hidrelétrica de Tucuruí e complexos Industriais, como os de produção de alumínio, que vêm causando a "[...] diminuição de pescado, o empobrecimento ainda mais das comunidades [...]", conforme dispõe Rodrigues (2012, p. 220), intensificando, desse modo, desigualdades sociais, mais intensamente afloradas no contexto da pandemia por Coronavírus que assola, também, o Baixo Tocantins, onde mais de 50\% da população de seus municípios apresentam domicílios com rendimentos mensais de até meio salário mínimo por pessoa. Esse é o caso de Cametá, com $55.4 \%$ da população inserida nessas condições, conforme dados de 2017 (IBGE) ${ }^{9}$, constituindose, portanto, em territórios de intensa pobreza.

Entretanto, opondo-se à destruição da vida, contraditoriamente, como sujeitos de história, homens, mulheres, jovens, adultos, crianças, pescadores e pescadoras artesanais vão também produzindo a vida, aqui exposta em imagens do trabalho e em instrumentos por eles e por elas realizado/produzidos, respectivamente. E pactuando com as reflexões de Magalhães e Tiriba (2018) sobre a categoria experiência, diríamos que são homens e mulheres que, vivendo em sociedade - comunidades ribeirinhas, vão, por meio do trabalho e das experiências daí decorrentes,

[...] atuando e transformando a realidade de acordo com o acúmulo histórico, material e cultural de experiências vividas, mas também transmitidas e apreendidas no seio da realidade material, formando

\footnotetext{
${ }^{9}$ Acesso a partir de < https://cidades.ibge.gov.br/>.
} 
verdadeiros repertórios de aprendizagens sociais, que são acionados de acordo com as necessidades concretas e psicossociais coletivas (MAGALHÃES; TIRIBA, 2018, p. 16).

Por fim, salientamos que o ensaio que aqui apresentamos decorre de experiências de trabalho captadas por meio de fotografias, como alhures já enfatizamos, que retratam esses verdadeiros repertórios de aprendizagens sociais, [...] acionados de acordo com as necessidades concretas e psicossociais coletivas, de que nos falam Magalhães e Tiriba (2018), partindo-se de uma compreensão da fotografia, conforme Ciavatta (2007, p. 35), "[...] como resultado da atividade social, o visível revelado e o invisível oculto, a história sob a aparente simplicidade de uma representação, a imagem", entendendo-se ainda, de acordo com Ciavatta (2007, p. 35), a fotografia como mediação, do que resulta "[...] concebê-la como processo social complexo (Ciavatta, 2002), síntese de múltiplas determinações ou o concreto pensado Marx (1977, p. 229) [...]", constituindo-se como "[...] uma visão historicizada de objetos singulares ou de acontecimentos, fenômenos cujo conhecimento deve ser buscado no conjunto articulado de relações sociais (estéticas, culturais, econômicas, políticas etc.) que o constituem no tempo e no espaço".

\section{As fotografias e o trabalho de pescadores e pescadoras artesanais}

Abaixo, apresenta-se um conjunto de fotografias que dizem respeito a tecnologias criadas pelos pescadores e pelas pescadoras, a partir do trabalho que realizam, assim como saberes sociais daí decorrentes, oriundos das relações que travam entre sim e com a natureza.

\subsection{O Paredão: uma forma de captura de pescado}

O paredão consiste em uma enorme parede feita de caule de açaizeiro (paxiba) ou de paxiubeira (árvores nativas da região), trançada com cipó de timbuí, vegetal da região. Esse equipamento tem o objetivo de capturar o pescado nas margens próximas das ilhas. Esse paredão é construído nas praias ou próximo das ribanceiras para dentro do rio. Possui 2 ou 3 gaiolas posicionadas no meio e nas extremidades, construídas com uma tecnologia nativa onde as entradas das mesmas são feitas em 
forma de "V", por onde os peixes entram e não conseguem sair. Esse equipamento de pesca, por ter grande porte, é normalmente construído para durar anos, não sendo removido pelos pescadores.

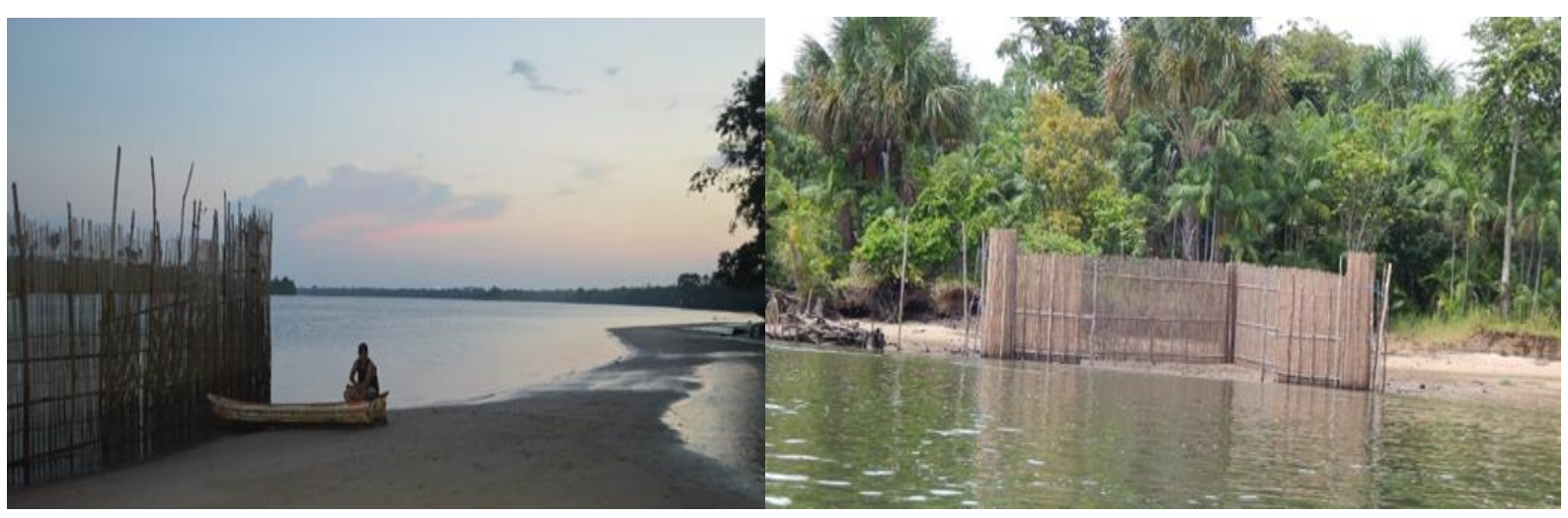

Fonte: Jurandir da Cruz Viana/Gilson da Silva Costa

\subsection{Matapí: a captura de camarões}

Consiste em uma gaiola em formato cilíndrico que possui, nas extremidades, entradas em formato cônico; no meio, possui uma portinhola que serve para a coleta do pescado. O matapí é utilizado para a captura de camarão. O crustáceo é capturado quando entra por uma das extremidades cônicas do equipamento, em busca do alimento (isca geralmente de babaçu), o qual é previamente colocado no interior do apetrecho; uma vez dentro, o camarão não consegue encontrar a saída.
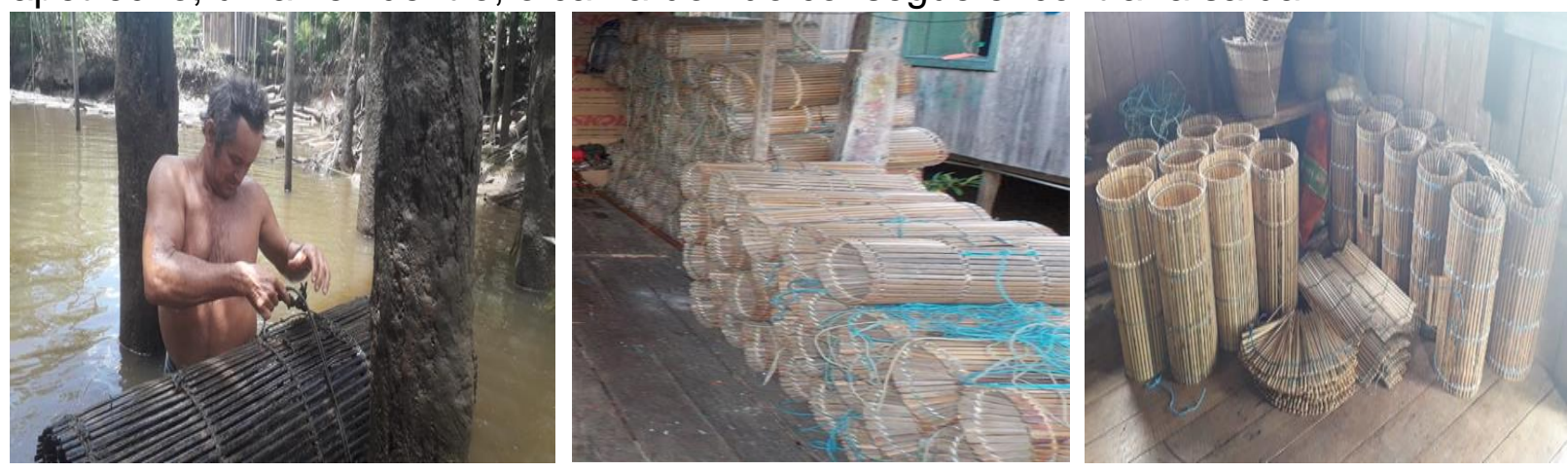

Fonte: Jurandir da Cruz Viana/Gilson da Silva Costa/Sara Corrêa Dias

O matapí é confeccionado comumente com talas retiradas da palmeira jupatí e pode, também, ser feito com o caule da palmeira marajá. É trançado por fibras de jacitara (cipó espinhento comum na região) ou fibras de buritizeiro e arumã (vegetais da região). Os mais comuns possuem mais ou menos meio metro de comprimento por 25 a 30 centímetros de diâmetro, podendo ser maiores conforme a utilidade. Os 
matapis são armados nas praias ou igarapés e são fixados por uma vara, que é enterrada para servir de suporte. O pescador geralmente liga os matapis uns com os outros através do cipó de timbuí, o que facilita a chamada despesca, que geralmente é realizada utilizando-se um casco (canoa).

\subsection{O Paneiro: instrumento de transporte de produção}

O paneiro é o utensílio mais utilizado por pescadores e pescadoras ribeirinhos na no Baixo Tocantins, existindo uma enorme variedade dele. Serve, conforme tamanho e forma, para vários usos, possuindo nomes diferentes, como pairé, paneiro de costa, dentre outros. É utilizado, por exemplo, para o carregamento do açaí, do pescado, de aves e até para acondicionar pães. Na foto, trabalhadora faz a coleta do açaí, numa operação chamada de debulha, quando os frutos são retirados dos cachos.

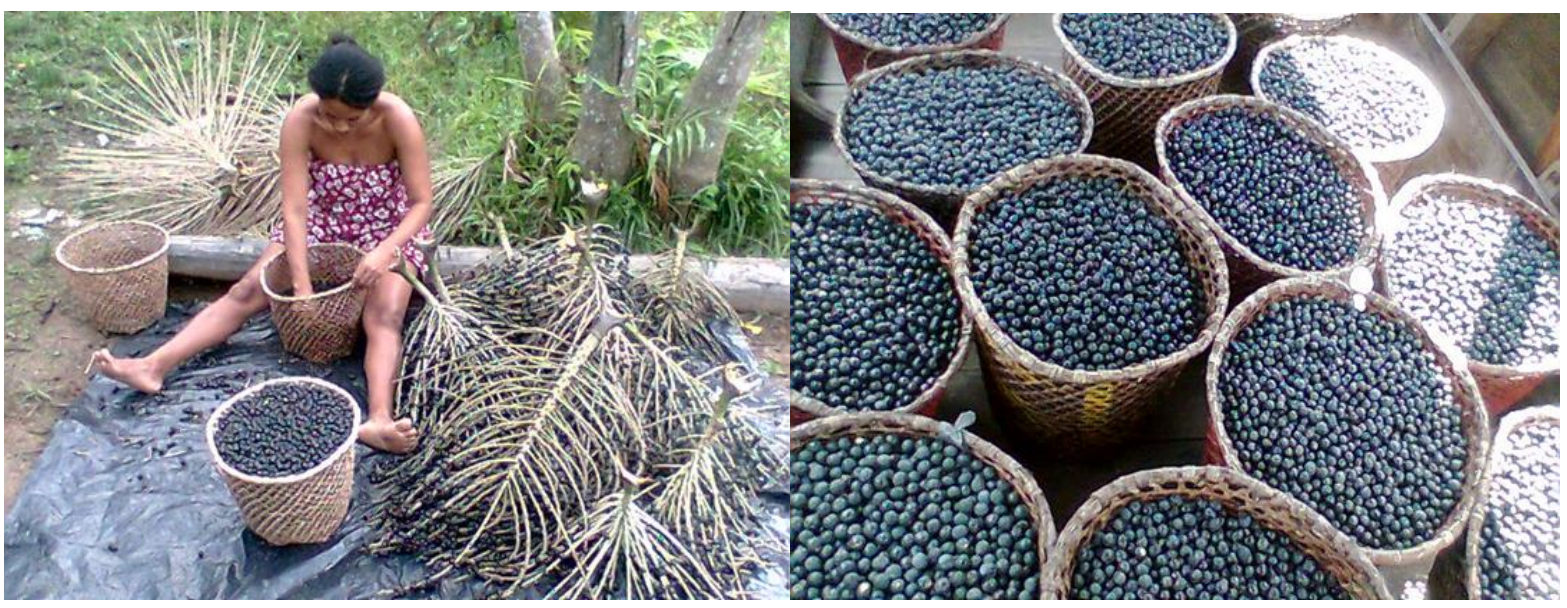

Fonte: Arquivo IDEAS - Instituto de Desenvolvimento Econômico e Assistência Social

O paneiro é confeccionado com fibras retiradas de várias árvores da região, como o arumã, a jacitara e o buriti. A matéria prima é retirada no mato e depois é limpa, transformada em fibra e posta no sol para secar. Geralmente esse trabalho é realizado por mulheres que confeccionam o paneiro em suas próprias casas ou em barracões comunitários nas ilhas.

O tamanho do paneiro varia de acordo com sua utilidade, o que vale também para a escolha da fibra a ser utilizada na confecção do objeto. Geralmente, para o carregamento do açaí, é utilizada a fibra de jacitara, por ser mais resistente. Muitas vezes utilizam-se duas fibras, que são alternadas na hora do trançar. 


\subsection{O Casco e o Remo: possibilidade de locomoção}

O casco é embarcação a remo bastante utilizada pelos pescadores e pescadoras do Baixo Tocantins. É uma espécie de canoa confeccionada a partir do tronco de algumas árvores amazônicas, tais como a andiroba, o ipê, a itaúba, o lourovermelho, a maçaranduba, o piquiá, a sapucaia, a tatajuba.
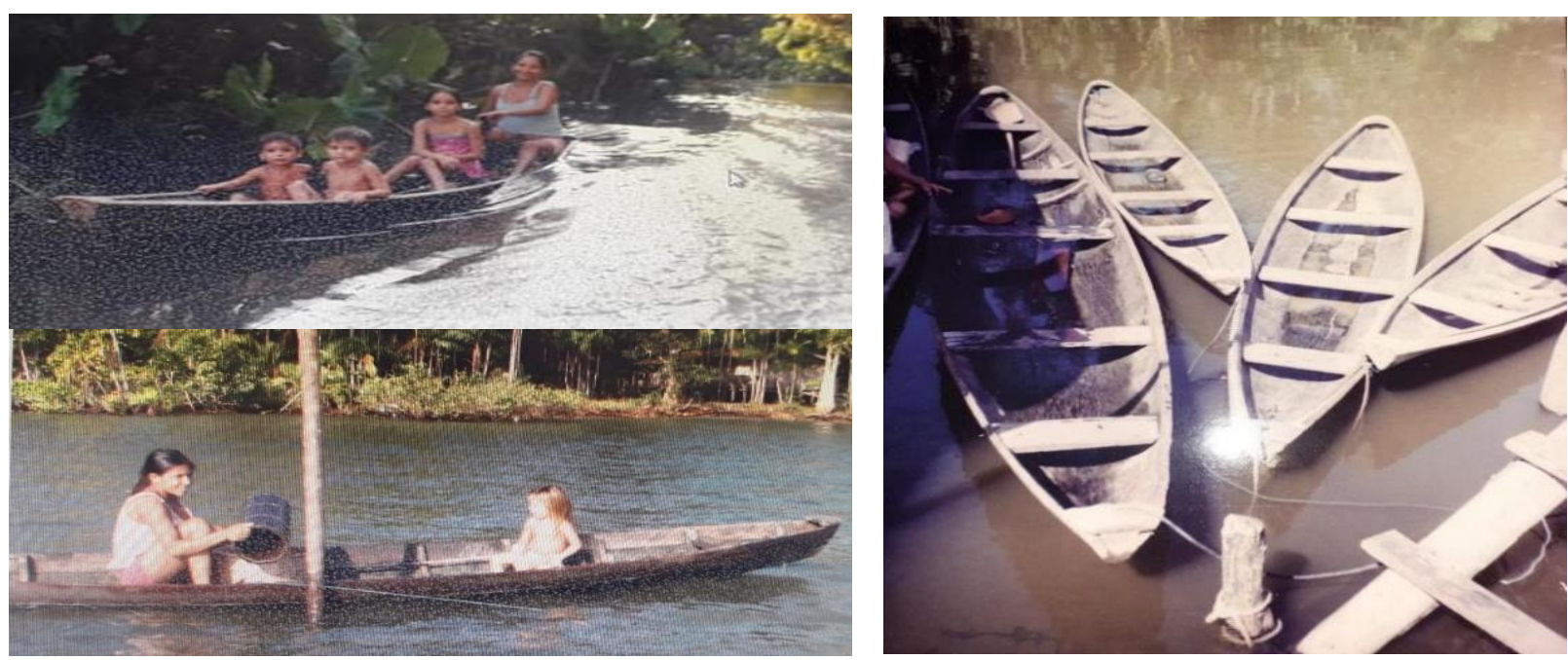

Fonte: Jurandir da Cruz Viana/Arquivo IDEAS ${ }^{10}$

O casco é quase sempre construído no mesmo lugar onde se corta a árvore escolhida para a sua fabricação. A tora é descascada com machado e enxó; em seguida é riscado (demarcado), fazendo-se a cavação do tronco para a retirada do âmago. Em tal procedimento é comum usar o fogo para desbastaro cerne da madeira. Após cavado, o trabalhador põe fogo na barriga da embarcação, que é posta com o oco para baixo (de boca para baixo), a fim de que sofra um processo de dilatação, ficando, portanto, mais larga. Nesse momento, é feito o envaramento, para que o casco tome forma. $\mathrm{O}$ acabamento é realizado com o uso do machado, enxó, plaina e arco de pua.

Os remos geralmente são confeccionados com as mesmas madeiras que são utilizadas para a construção do casco. São os instrumentos essenciais para movimentar a embarcação. Possuem cabos cilíndricos e com as extremidades em forma de folhas arredondadas. No acabamento são utilizadas ferramentas como a

${ }^{10}$ Instituto de Desenvolvimento, Educação Ambiental e Solidariedade (IDEAS). 
enxó, o machado, plainas e raspadores, que servem para deixar os remos bem lixados.

\subsection{Bloqueio ou Borqueio na pesca do mapará: um trabalho colaborativo}

Bloqueio ou borqueio, como é comumente falado por muitos ribeirinhos do Baixo Tocantins, é um tipo de pesca que acontece principalmente no período da abertura da pesca na região. O borqueio é visto mais corriqueiramente durante a captura do mapará, peixe da região, acontecendo inicialmente com a reunião dos pescadores de determinada área comunitária, que escolhem o poço a que devem se dirigir na busca do peixe.
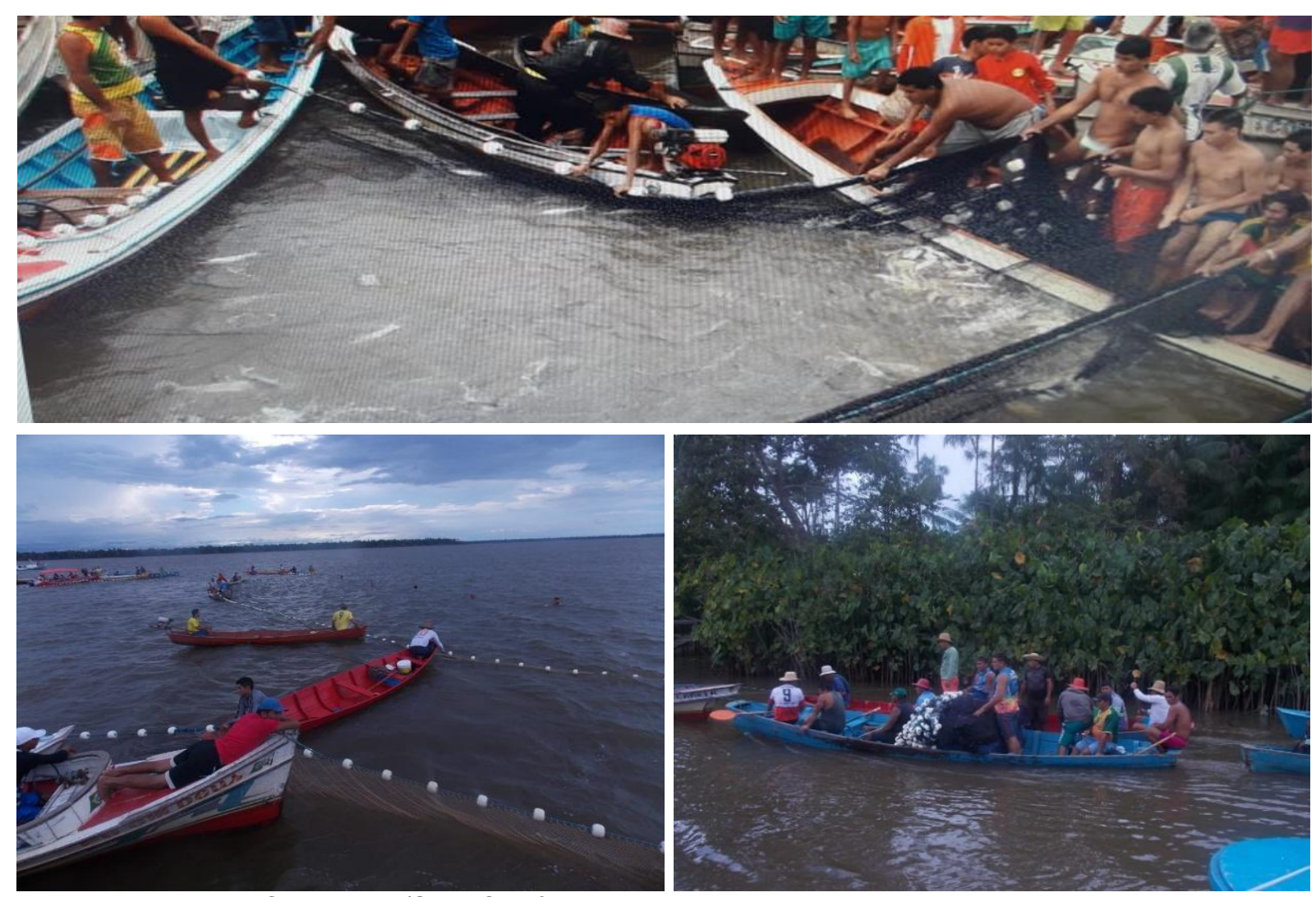

Fonte: Jurandir da Cruz Viana/Sara Corrêa Dias

Existe, nessa pesca, todo um ritual que envolve a descoberta do cardume e de seu tamanho pelo taleiro. O taleiro é um pescador que, armado de uma vara de aproximadamente 3 metros de comprimento e sentado na proa do casco, pratica uma espécie de sondagem ao afundar a vara no rio. Ao fazê-lo, sente as vibrações 
provindas do cardume e, através desse ato, é capaz de identificar a direção e a quantidade de peixe no local.

Feita a sondagem pelo taleiro, a rede é jogada no rio, ao que entram em cena os mergulhadores, que têm o objetivo de imergir por baixo do cardume e costurar a rede. A costura é feita com cordas que amarram as redes por baixo, formando uma espécie de saco onde o peixe é preso. Logo em seguida, os pescadores se aproximam, puxando a rede e formando uma espécie de círculo. Ao puxarem as cordas da rede, esta vem à tona, trazendo com ela o cardume inteiro, que aflora na superfície do rio e então, a partir desse momento, os pescadores fazem a coleta do mapará, utilizando os paneiros, que são cheios e colocados nas embarcações. A partir daí o pescado é dividido entre os pescadores e os moradores da comunidade onde fica o poço de pesca. Em seguida, todos retornam a suas casas.

\subsection{0 trato do pescado em colaboração no cotidiano da casa}

É bem comum na Amazônia, no contexto de trabalhadores e trabalhadoras da pesca artesanal, o trabalho/preparo de utensílios ou até a realização de refeições no assoalho de suas casas. Assim, não raras as vezes observamos no assoalho da sala ou da cozinha trabalhadores e trabalhadoras do Baixo Tocantins ligados à pesca artesanal confeccionando paneiros, tipitis, esteiras, abanos e outros instrumentos. Nas imagens, homens e mulheres nos cuidados do pescado mapará e também em almoço, em vivência a partir do comum.

Por outro lado, o chão da casa não serve apenas para fazer os trabalhos corriqueiros ou refeições, mas também para tirar a sesta da tarde, que é um repouso depois do almoço. Esse espaço é utilizado pelos mais velhos que, sentados ou deitados no chão liso de madeira, contam histórias para as crianças ou recebem os amigos para uma conversa informal, distraída e alegre. É um espaço de convivência familiar e social. 

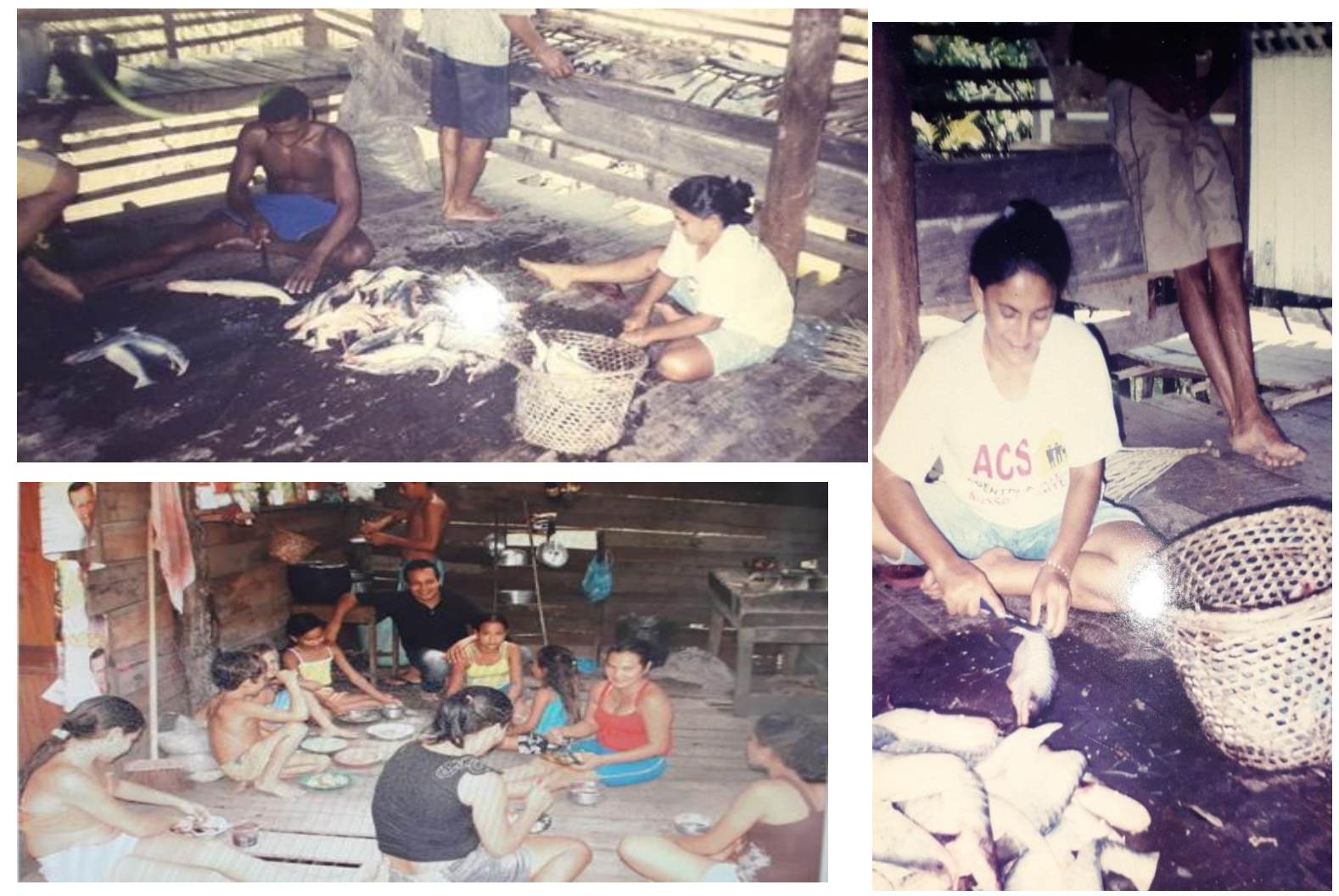

Fonte: Jurandir da Cruz Viana/ Arquivo IDEAS

\subsection{Muquém ou Moquém: a técnica do assado do mapará}

O Muquém é uma prática indígena de assar muito antiga, ainda utilizada por trabalhadores e trabalhadoras da pesca do Baixo Tocantins, e que consiste em assar peixes e carnes. Comumente, essa prática está ligada, nessa região, ao assado do peixe, principalmente ao mais apreciado nas ilhas, o mapará.
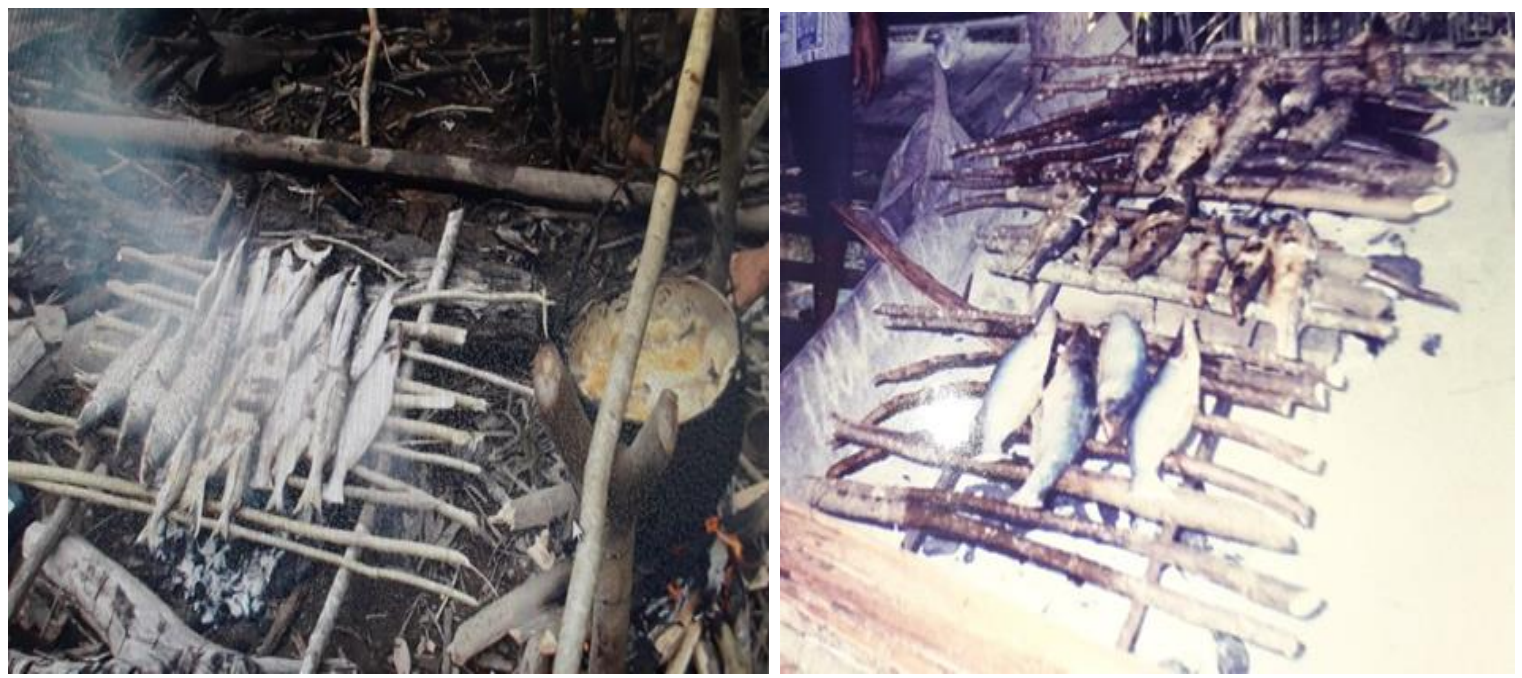

Fonte: Jurandir da Cruz Viana/ Arquivo IDEAS 
O assado do mapará, ou moquém, é feito com o pescado logo após a sua retirada do rio. Trata-as do conhecido mapará muquiado, que é lanhado, riscado e posto para assar no muquém, o qual é preparado geralmente no terreiro ou em um fogão de barro a lenha. Consiste em apoiar algumas varetas em pedaços de vara maiores, colocados nas laterais. Embaixo das varetas trançadas é acesa a brasa, feita com lenha ou carvão. O pescado é jogado em cima das varetas, onde é tostado e temperado apenas com limão e sal, alimentando, no chão das casas, um conjunto de famílias que vivem da pesca artesanal no Baixo Tocantins.

\section{Considerações - em síntese - sobre as imagens e os saberes sociais do trabalho de pescadores e pescadoras}

Neste trabalho, tomamos algumas fotografias que expressassem pequenas e intensas cenas da historicidade de homens e mulheres ribeirinhos, em relações entre si e com a natureza, resultando na produção de instrumentos de pesca e de coleta de outros recursos das florestas (como o fruto açaí), assim como em formas de captura do pescado, de transformação em alimento e de relações socioculturais. Trata-se de fotografias que expõem um conjunto de saberes sociais do trabalho desses sujeitos.

São saberes que caracterizam, de acordo com Rodrigues (2012, p. 54), “[...] o trabalho, em sua faceta não alienada [...], como "[...] o momento de constituição da humanidade do homem, porque lhe permite o exercício da engenhosidade, da criatividade, do planejamento e da execução do seu querer [...]", permitindo, conforme Schwartz (2003, p. 23), que "[...] toda atividade de trabalho [...] [encontre] saberes acumulados nos instrumentos, nas técnicas, nos dispositivos coletivos [...]" e que "[...] toda situação de trabalho [...] [esteja] saturada de normas de vida, de formas de exploração da natureza e dos homens uns pelos outros".

As fotografias aqui reunidas expressam, pois, situações de trabalho saturadas de normas de vida e indicadoras de processos importantes para a constituição de classe, como o viver coletivo e o sentir-se membro de uma totalidade social, posto que, de acordo com Thompson (1987), os homens se constituem como classe porque sentem e articulam uma identidade de interesses entre si, resultantes de experiências em comuns, herdadas ou partilhadas, produzindo saberes que, de acordo com Rodrigues (2012, p. 153) "[...] vão Ihes conferindo uma identidade diferenciada em 
relação a outros trabalhadores, identificando-os, do ponto de vista do trabalho, como aqueles que dominam conhecimentos relacionados ao cotidiano da pesca".

Como base em Souza (2020, p. 129), entende-se que as fotografias aqui reunidas expressam modos de vida de pescadores e pescadoras artesanais do Baixo Tocantins, compreendidos como um "[...] conjunto de práticas sociais, econômicas e culturais cotidianas compartilhadas por um determinado grupo social no processo de produção da vida material e simbólica", relacionando-se a "[...] costumes, tradições, valores, crenças e saberes que orientam as normas de convivência na vida familiar, no trabalho e em âmbito comunitário", bem como "[...] às maneiras de produzir, consumir e distribuir os frutos do trabalho, tendo em conta as formas de sentir e pensar a vida e o mundo".

\section{Referências}

ALMEIDA, R. Amazônia, Pará e o mundo das águas do Baixo Tocantins. In: Revista Estudos Avançados, v. 24, n. 68, São Paulo, 2010. Disponível em: $<$ https://www.scielo.br/scielo.php?script=sci_arttext\&pid=S010340142010000100020>. Acesso em: 10 mar. 2020.

CIAVATTA, M. O espaço da fábrica para o espaço da escola (i): introdução a uma história fotográfica. In: (Coord.); DUARTE, Elisa Tavares et. al. Memória e temporalidades do trabalho e da educação. Rio de Janeiro: Lamparina: FAPERJ, 2007.

FURTADO, L. Pescadores do rio Amazonas: um estudo antropológico da pesca ribeirinha em uma área amazônica. Belém: MPEG, 1993.

HELLER, A. O cotidiano e a história. São Paulo: Paz e Terra, 2008.

MAGALHÃES, L. D. R.; TIRIBA, L. Introdução: Experiência - o Termo Ausente. In: MAGALHÂES, L. D. R.; TIRIBA, L. (Orgs.). Experiência: o termo ausente? Sobre história, memória, trabalho e educação. Uberlândia: Navegando Publicações, 2018.

MARX, K. O Capital: crítica da economia política. v. 1. Rio de Janeiro: Civilização Brasileira, 2008.

MORAES, S. C. de. Uma arqueologia dos saberes da pesca: Amazônia e Nordeste. Belém: EDUFPA, 2007.

NEVES, D. P. Os ribeirinhos-agricultores de várzea: formas de enquadramento institucional. Revista Novos Cadernos NAEA, v. 12, n. 1, p. 67-92, jun. 2009. 
RODRIGUES, D. do S. Saberes sociais e luta de classes: um estudo a partir da colônia de pescadores artesanais Z-16 Cametá/ Pará, 2012. 337f. Tese (Doutorado em Educação) - Programa de Pós-Graduação em Educação, Instituto de Ciências da Educação, Universidade Federal do Pará, Belém.

SOUZA, W. K. do A. Trabalho-Educação, Economia e Cultura em Povos e Comunidades Tradicionais: A (Re)Afirmação de Modos de Vida como Formas de Resistência. 2020. 222f. Tese (Doutorado em Educação) - Programa de PósGraduação em Educação da Universidade Federal Fluminense, Niterói -RJ.

THOMPSON, E. P. A formação da classe operária inglesa. 2. ed. v. 1 Rio de Janeiro: Paz e Terra, 1981.

Tempo, disciplina de trabalho e capitalismo industrial: costumes em comum - estudos sobre a cultura popular tradicional. São Paulo: Companhia das Letras, 2005. 